\title{
Tumor necrosis factor alpha induced proliferation of adult neural stem cells is mediated via NF- $\kappa \mathbf{B}$ \\ Darius Widera*, Ilja Mikenberg, Margitta Elvers, Christian Kaltschmidt and Barbara Kaltschmidt
}

\author{
Address: University of Witten/Herdecke, Institute for Neurobiochemistry, Witten, Germany
}

* Corresponding author

\author{
from Annual Meeting of the Study Group Neurochemistry. International Conference of the Gesellschaft für Biochemie und Molekularbiologie 2006 (GBM \\ 2006): Molecular pathways in health and disease of the nervous system \\ Witten, Germany. 28-30 September 2006 \\ Published: 23 March 2007 \\ BMC Neuroscience 2007, 8(SuppI I):PI doi:I0.1 186/I47I-2202-8-SI-PI
}

(c) 2007 Widera et al; licensee BioMed Central Ltd.

Brain inflammation is a very complex phenomenon with several related aspects. Besides the neurodegenerative effect of inflammation, inflammatory signals exert a positive influence on neural stem cell proliferation, migration and differentiation. Large parts of the inflammatory signal transduction can be considered as an innate immune response triggered by TNF. The purpose of the present study was to investigate the signal transduction mechanisms induced by TNF.

Here we show that TNF-mediated signal transduction cascade results in increased proliferation of neural stem cells (NSCs).

TNF strongly activated the transcription factor NF- $\mathrm{KB}$ as showed by immunocytochemical analysis and reporter gene assays. Furthermore, TNF treatment significantly upregulated the Cyclin D1 level, which correlated with increased proliferation of NSCs.

Since the proliferation of most tumour cells described up to date has been shown to be largely NF- $\kappa B$ and Cyclin D1 dependant, this study might provide a common denominator between neural stem cell and tumour cell proliferation control. Understanding of these mechanisms might be important to avoid side effects of tumor therapy (unintended killing of stem cells by NF- $\kappa B$ inhibition). On the other hand, understanding proliferation control of stem cells might be crucial for future therapeutic strategies. 